\title{
IBM Watson Industry Cognitive Education Methods
}

\author{
Rajeshwari $\mathbf{M}^{1,2}$ \& Krishna Prasad $\mathrm{K}^{3}$ \\ ${ }^{1}$ Research Scholar, College of Computer Science and Information Science, Srinivas \\ University, Mangalore, India \\ ${ }^{2}$ Assistant Professor, Dept of Computer Science, St Philomena College, Puttur, India \\ ${ }^{3}$ College of Computer Science and Information Science, Srinivas University, Mangalore, \\ India \\ E-mail: rajimuraleedhar@gmail.com
}

Area of the Paper: Information Technology.

Type of the Paper: Case Study Paper.

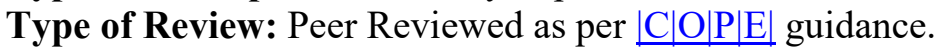

Indexed In: OpenAIRE.

DOI: http://doi.org/10.5281/zenodo.3766900.

Google Scholar Citation: IJCSBE.

\section{How to Cite this Paper:}

Rajeshwari, M., \& Krishna Prasad, K. (2020). IBM Watson Industry Cognitive Education Methods. International Journal of Case Studies in Business, IT, and Education (IJCSBE), 4(1), 38-50. DOI: http://doi.org/10.5281/zenodo.3766900.

International Journal of Case Studies in Business, IT and Education (IJCSBE) A Refereed International Journal of Srinivas University, India.

(C) With Authors.

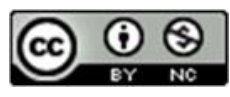

This work is licensed under a Creative Commons Attribution Non-Commercial 4.0 International License subject to proper citation to the publication source of the work.

Disclaimer: The scholarly papers as reviewed and published by the Srinivas Publications (S.P.), India are the views and opinions of their respective authors and are not the views or opinions of the S.P. The S.P. disclaims of any harm or loss caused due to the published content to any party. 


\title{
IBM Watson Industry Cognitive Education Methods
}

\author{
Rajeshwari $\mathbf{M}^{1,2}$ \& Krishna Prasad $K^{3}$ \\ ${ }^{1}$ Research Scholar, College of Computer Science and Information Science, Srinivas \\ University, Mangalore, India \\ ${ }^{2}$ Assistant Professor, Dept of Computer Science, St Philomena College, Puttur, India \\ ${ }^{3}$ College of Computer Science and Information Science, Srinivas University, Mangalore, \\ India
}

\begin{abstract}
Data analytics converts bulk of data into insights for business, healthcare, insurance and education. An upcoming development in IBM's data analytic approach towards education is cognitive learning systems. Human being and machine can communicate each other by the technologies that use Natural Language processing and Machine Language together in action. Presently, many students struggle for their education without any goals. In this sense, cognitive systems should improve student education and results with a customized perception of their learning. IBM has recently pointed his service on education by its supercomputer or computing technology, IBM Watson. Such systems can provide an expert assistant to all varies of professionals in their respective fields. It is also being used widely to assess student performance and to help educators in the classroom develop more constructive instructional practices for their students. It helps the teacher to collect attendance, marks detail and to analyse the individual student's interest based on his result. This industrial analysis will explain the power of data analytics in classroom by the teachers to assess the student's personal behaviour and the way it is used as a tool by the teachers to determine student's interest in finding the better career. Based on individual student outcome, Watson using AI will find solutions to improve quality and policy of education. Here AI technology gives tools to the teachers they need to be most effective and help learners perform at the top of their abilities like tutors, childhood vocabulary development and personalizes content for students based on mastery. Data Digital services and apps are used on learning and they help in the learning experience. This study will help to understand the way different technologies working together in predictive analytics and to prepare a report on admission, number of attendances, student dropout rate, their result analysis and their future. This study will analyse the success rate of personalised education of student using cognitive learning skills.
\end{abstract}

Keywords: IBM Watson, AI, Machine Learning, Cognitive Systems, Learning, Natural Language Processing.

\section{INTRODUCTION :}

The structure of the education system is common to all students, regardless of their potential and ability to learn. Each student is a common part of the class or school, with a single teacher and a specific curriculum. But each student has a distinct socio-economic background, quality and ability to understand. The system is not personalized or built on the needs of the individual student. The student scorecard may not be considered to assess his or her talent or skill during the student's admission. Because many factors may have an impact on the decline or growth of the student's grade. This statistical model would fail if, after admission, the student is driven to achieve better performance in school. Students therefore need good motivation, courage to face unforeseen challenges in life, hard work and a good curriculum in all directions of learning. The field of education provides bulk amount of data with multiple challenges. The teacher's challenge here is to find out what data needs to be collected for the planning of the syllabus, the teaching policy for building a student for his future. 
Teachers should become educators by using advanced data analytics technology. New technologies should transform the way students now have access to educators in order to make the best use of the available technologies [1]. The most successful company in the world, IBM, has focused its attention on educational analytics. Better academic strategies, plans even education programs are the results of data analytics, which transforms a large part of the data into information for policymakers and educators. It converts student-data volumes to intelligence, leads to the creation of a smarter school. This emerging technology, known as the cognitive learning system, builds on neuroscience-based approaches that develop brain-based computing and artificial network algorithms [2]. It works on perception, action and cognition of human brain. This results in the production of Watson, a cognitive supercomputing system. Watson is a computer replying question that can answer all natural-language questions. It's the product of IBM. This computer system was originally designed to answer questions about the 2011 Jeopardy quiz show. It was able to answer all the questions posed by legendary champions Brad Rutter and Ken Jennings and won first place with a reward of one million dollars [3].

\section{RELATED WORK :}

The Watson computer system was introduced in 2011, in order to compete on the Jeopardy quiz to answer questions posed in natural language. Later in February 2013, the first commercial application of the Watson system was introduced in New York, when decisions were taken in the treatment of lung cancer. Even if it was introduced as a question answering system, IBM did it to build application on automated reasoning, decision making, machine learning, retrieval of information and representation of knowledge in healthcare, business, finance, social and education. Watson capabilities have been expanded in recent years as it could build new deployment models for developers with cloud, machine learning, and optimized hardware. Not only is it a QA machine but it can also have cognitive computing capabilities. Like humans, it can have 5 sensory actions. IBM's Watson machine is a cognitive computer implemented using deep learning and neural networks [2]. Some of the scholarly published papers on Watson with cognitive computing are studied and listed in table 1 along with references in the various field of education.

Table 1: Related IBM Watson publications by various researchers on different fields.

\begin{tabular}{|l|l|l|l|}
\hline Year & $\begin{array}{l}\text { Area } \\
\text { Application }\end{array}$ & Findings/Focus & Reference \\
\hline 2011 & Education & $\begin{array}{l}\text { In order to detected concepts and relations in the } \\
\text { text (presented in natural language), Watson uses } \\
\text { statistical and other rules based methods. }\end{array}$ & $\begin{array}{l}\text { Lally, A., \& Fodor, } \\
\text { P. [4] }\end{array}$ \\
\hline 2012 & Healthcare & $\begin{array}{l}\text { Watson was built to handle text, but needs more on } \\
\text { other medical field areas such as surgical videos, } \\
\text { dermatological photographs, other non-text-based } \\
\text { medical information, etc. }\end{array}$ & Arnaout, R. [5] \\
\hline 2013 & Thinking Machine & $\begin{array}{l}\text { With artificial intelligence Watson could answer all } \\
\text { questions. Therefore, machine with AI technologies } \\
\text { as human can be used in the medical sector. }\end{array}$ & Brown, E. W. [6] \\
\hline 2014 & $\begin{array}{l}\text { Extract knowledge } \\
\text { from syntactic and } \\
\text { semantic relations }\end{array}$ & $\begin{array}{l}\text { Extracting the propositions from the Wikipedia and } \\
\text { New York Times English versions. }\end{array}$ & $\begin{array}{l}\text { Exner, P., } \\
\text { Nugues, P. [7] }\end{array}$ \\
\hline 2014 & $\begin{array}{l}\text { Education } \\
\text { Theoretical computer science course found by the } \\
\text { Potsdam University students tough. The cognitive- } \\
\text { learning-based pedagogical approach made the } \\
\text { students respond very well by a success rate of 94 } \\
\text { per cent in the final exams. }\end{array}$ & $\begin{array}{l}\text { Knobelsdorf, M., et } \\
\text { al. [8] }\end{array}$ \\
\hline 2014 & $\begin{array}{l}\text { Education } \\
\text { Healthcare }\end{array}$ & $\begin{array}{l}\text { Using technology, future physicians can make use } \\
\text { of Watson to improved practice medicine in the } \\
\text { spirit of Osler. }\end{array}$ & $\begin{array}{l}\text { Colbert, J. A., et al. } \\
\text { [9] }\end{array}$ \\
\hline
\end{tabular}




\begin{tabular}{|l|l|l|l|}
\hline 2015 & Public Sector & $\begin{array}{l}\text { IBM Watson can make 70 percent of financial } \\
\text { transactions, which will make it possible for all its } \\
\text { social demands to work with customers. }\end{array}$ & Helbing, D. [10] \\
\hline 2016 & Education & $\begin{array}{l}\text { Three applications were developed by university } \\
\text { teams, to prepare educational content in the health } \\
\text { care and tourism domain, using deep learning and } \\
\text { answering questions on Watson system. }\end{array}$ & $\begin{array}{l}\text { Kollia, I., \& Siolas, } \\
\text { G. [11] }\end{array}$ \\
\hline 2016 & $\begin{array}{l}\text { Life Science } \\
\text { Research }\end{array}$ & $\begin{array}{l}\text { To gain knowledge on difficult patient cases, } \\
\text { Watson was able to read published journal articles. } \\
\text { These data gathered evaluate the new challenges in } \\
\text { the field of life science. }\end{array}$ & Chen,Y, et al. [12] \\
\hline 2017 & Education & $\begin{array}{l}\text { Watson Dialog Service can help identify common } \\
\text { bugs and mistakes in OpenMp programs. }\end{array}$ & $\begin{array}{l}\text { Chozas, A. C., et } \\
\text { al. [13] }\end{array}$ \\
\hline 2018 & $\begin{array}{l}\text { Analysis of Public } \\
\text { Data }\end{array}$ & $\begin{array}{l}\text { IBM Watson cognitive service is capable of } \\
\text { extracting personality traits from text and visual } \\
\text { recognition to analyze images from social network } \\
\text { posts such as Facebook. }\end{array}$ & Balogh, Z. [14] \\
\hline 2019 & Agriculture & $\begin{array}{l}\text { In agriculture, IBM Watson's visual recognition } \\
\text { tool can be used to find problems with irrigation } \\
\text { system strategies using cloud-based AI services. } \\
\text { Such tool can help irrigation system monitor crop } \\
\text { status to maximize the sustainable use of water. }\end{array}$ & $\begin{array}{l}\text { Freeman, D., et al. } \\
\text { [15] }\end{array}$ \\
\hline 2020 & Healthcare & $\begin{array}{l}\text { The AI-equipped machine can generate user } \\
\text { knowledge by using nearly 80 per cent (structured } \\
\text { or unstructured) of data in any field or business. }\end{array}$ & Garcia, C., \& \\
Uzbelger, G. [16]
\end{tabular}

\section{OBJECTIVES OF THE STUDY :}

Watson is the IBM suite for IT services, applications and tools that is ready for use by companies. The study is limited and focused to analyse an industry IBM based on its tool used for education-Watson. The main objectives are:

- To explore the business strategy of the company using Watson

- To explore the components of IBM Watson

- To explore the benefits of using it in education

- To find the huge data storage used by the company

- To find the education partners and academic initiatives of IBM

\section{REASEARCH METHODOLOGY :}

This industrial analysis is prepared by collecting secondary data from IBM websites and published journals. The evaluation is done using developed by referring journals, articles, newspapers and websites etc.

\section{BUSINESS STRATEGY :}

Successful companies are always thinking about the new strategy to meet future markets 'hunger and customers' competitive demands. In order to find new opportunities in business, exponential technologies are applied to the business. Executives and knowledge workers use analyzed data to take effective business decisions. Using human imagination and creativity, Watson's algorithms are used to analyze structured and unstructured data to get the best results. This is where AI benefits take the lead. Here, AI data is evolved to actionable intelligence using cognitive services belonging to the family Watson. IBM Watson, the machine can handle the critical business tasks and decisions and automate them. Customer's emotions are analyzed for the fruitful customer service to be found. Company is provided with Watson Knowledge Studio to study the terminology and language of the company that is developed on Watson's understanding of the natural language. Watson's AI engine takes advantage 
of data visualization tools to extract complex data from clients. The generation of chat bots and dashboards improves customer experience [17]. Cognitive business solutions help business leaders find the return on the investments to think about business in reality. These new solutions are applied on four strategic ways in IBM's business.

\section{- Construct Tactical Business Relationships}

Business data including competitors, financial data, performance gaps etc are automatically read and analyzed by cognitive systems, which use natural language processing and machine learning to save time and manpower. Computers may identify news and source of knowledge into specific business categories such as mergers and acquisitions through services like entity recognition. This will lead to business growth.

\section{- Make Better Decisions}

Company needs multiple meetings for every business decision. Tradeoff Analytics allows people to take decisions by using Pareto Optimization, a mathematical filtration method, as they combine many thoughts. The program eliminates such meetings and allows people to make better choices by avoiding unnecessary meetings.

\section{- Improve Communications}

Interior and external contact will lay the foundations for success and failure. Do you ever wonder how your customer or boss will interpret your message? Emotion, social patterns and linguistic style can be identified by text linguistic analysis. Tools for tonal analysis help companies enhance the efficacy and delivery of messages, improving the impact of the message on customers, employees and clients.

- Increase Bandwidth: Employees are searching for information for most of 2.5 hours a day. Technology helps reduce manual effort and time by increasing high goal achievement opportunities. Cognitive services that contribute to strong customer service, competitive ability, etc [18].

\section{PROTOTYPE OF COGNITIVE LEARNING SYSTEMS :}

Cognitive system is a blend of technologies which use the processing of natural languages and machine learning. These technologies allow human beings and machines to interact naturally to improve human knowledge and knowledge. In this regard IBM has developed a program of cognitive computing for learning. Here intelligence and neuroscientific knowledge work together in neurotechnology cognitive learning processes. This prototype developed by IBM includes automated cognitive learning content, cognitive tutors and cognitive learning assistants. It is designed to understand the needs of the learner, to provide constant support and personalized education for the student. Watson Teacher Advisor, an application created by IBM, can track, analyze and assess information in order to make decisions that will allow teachers to direct and encourage students to improve their teaching [2].

(a) Cognitive Learning Content: Initially the IBM research group develops working models with likeminded institutions in order to prepare the content of the current education system. Watson, the US game-winning machine used as a cognitive computer communicates with human beings in a natural way by queries The contents are prepared, (i) with a deep knowledge of cognitive neuroscience and cognitive process algorithms (ii) to gather feedback that evaluates informs and refreshes the contents in order to improve learning efficiency. Finally, learning content has a vision of personalized learning and of engaging learners with positive outcomes everywhere [2][20].

(b) Cognitive tutor: It is an adaptive tutoring system that uses cognitive models to make the best recommendations when they face problems. It provided the correct interface for student communication to take the next successive steps. It also provides problem-solving skills by practice and context specific clues at the student's query. It also relies on the option of individual issues. It collects feedback on their performance by using cognitive models to improve the direction of learning through individual attention.

Tutor works on a cognitive model using two algorithms to implement its work. They are model tracing and knowledge tracing. Through model tracing, the individual path of the participant is identified as posing complex problems and collects input to improve the accuracy of the model and provides sufficient guidance on the specific context. Throughout knowledge tracing, the tutor uses the Bayesian method to test student knowledge in order to identify the problem faced by the individual 
student. Both tracing approaches are used to track student learning [2]. Watson tutor will assist teachers with the use of natural language processing to help students to clarify their questions on subject. [21]. (c) Teaching Assistant: IBM Watson is used in a variety of education programs. Pearson Education, Blackboard, Sesame Workshops and Apple are IBM's educational collaboration initiatives. With Pearson, IBM is able to adopt the natural language processing on electronic textbooks, a reading material that facilitates one-to - one tutoring for students. IBM and a few students has used Jill, a virtual teaching assistant, to assist students in the classroom. There is also an assistant available for parallel programming learning using IBM Watson. Specific requests or commands are answered by a software agent called an Intelligent Virtual Assistant (IVA) or an Intelligent Personal Assistant (IPA). Often chatbots are used as online chat virtual assistants [2].

(d) Watson Teacher Advisor: Watson's Teacher Advisor is a web-based instructional planning tool created by educators. It is designed for educators to prepare presentations and schedule successful coordinated lessons. For cognitive computing systems, the Teacher Advisor tool allows teachers to make the most of their ability to reach the student's ability, based on their context. This will not displace the teacher; instead, it builds or optimizes the recursive role of the machine cognition and human cognition in learning together. Here teacher with machine algorithms are augmented and extended. This will create cognitive classrooms that studies student's behaviour, to build a model of human brain through regular interactions between educators and non-human cognitive systems. This is also driven by artificial intelligence to answer all questions asked by students over the course of the semester [2]. It will improve the ability to learn not only in the classroom, but also outside.

\section{IBM WATSON EDUCATION :}

For student success, learning outcomes and implementation approaches are built by IBM Watson Education Team through AI. Watson AI technology will provide educators with tools to help students make the most of their abilities [22]. Watson cognitive computing digests volumes of knowledge from text, audio, video, and other media and makes the way for students to transform into a new education system. Such AI technologies should improve learner success and enable teachers to personalize learning for all types of students from pre-kindergartentoK-12and higher education to lifelong learning [23]. AI can be used in education by these three ways [22]:

(a)Based on ability of student contents are personalized: every student will get Lessons, activities and assignments based on where they are today and their ability to learn.

(b) Early childhood vocabulary development program: Tablet-based vocabulary learning apps are developed to identify the additional areas of learning to enhance their future of education.

(c) 1:1 AI-based tutoring for students: Each student will be tracked in order to identify his or her progress or failure to provide ideas for better solutions for the improvement of students by instructors [23].

IBM Watson Element and IBM Watson Enlight are the two important products provide by Watson Education. Watson Element can collect data on the educational, socioeconomic, and actions of students and allow educators to support and involve that student in the classroom. Watson Enlight highlights the academic strength, weakness of the student to plan lessons in a properly planned manner to meet the student's need for progress [21].

\section{IBM WATSON DISCOVERY :}

IBM Watson collects unstructured data from proprietary data, public data and third-party data to retrieve information or patterns for rapid cognitive, cloud-based applications. Unstructured information is collected using queries and we'll get the answers we need. They are then integrated into our new or existing application. IBM Watson Discovery offers APIs for searching, transforming, enriching, and normalizing data. It provides security to the data collected and adds additional enrichments such as ideas, relationships, and emotions by natural language comprehension. We can also position specific questions or customer inquiries to Discovery using the IBM Watson Assistant chatbot [24].

\section{IBM WATSON EDUCATION PARTNERS :}


IBM has announced a partnership with Scholastic and Edmodo to build a strong Watson Education platform. Scholastic Go and ScienceFlix Scholastic Libraries will provide content from different media, articles, etc. in IBM Watson Education. Edmodo provides educational content by the search engine AskMo and the Cognitive Library IBM Watson Classroom. It collects information in the cloud needed for training like books, test paper questions and lesson planning. This will help to categorize the plans and content based on the student's grade, age and interests [21]. IBM is linked to Sesame Workshop to develop Sesame's Intelligent Play \& Learning Platform vocabulary application. IBM has developed a series of equipment, games and toys based on cognitive technology. It also agreed with Blackboard and Pearson to implement IBM's educational system for public schools and universities in order to provide students with intelligent books as a reading material [21]. IBM is also associated with a Kendriyavidyalaya network to help mathematical teachers. The AI Powered Educational Resources website helps tutors prepare lesson plans and activities with good strategies [25]. IBM is also partnering with the Government of India and with IBM Watson Cognitive Engine, a platform that is developed with AI Powered Mentors, working with young innovators in Atal Tinkering Labs and preparing 4000 mentors and 6,00,000 staff. This offers personalized support for students. This project has produced 2,500 mentors, including 300 IBMers, in association with the National Mentor of Change Mission [25].

\section{PERSONALIZED LEARNING (ADAPTIVE LEARNING OR DIFFERENTIATED LEARNING) :}

Our educational system, supported by the universities, does not draw on the skills of graduates, which are very much required from the new job markets. Education should therefore find cognitive technology running on a lot of data, so as to allow personalized learning to develop knowledge and expertise for students, educators and administrators. This will boost learning style, speed, and interest in education [26].

Personalized learning is a new teaching paradigm in which each student receives his or her learning plan for his or her ability and goal. The plan is designed for his knowledge ability, interest, speed and style of learning. Here, therefore, the teacher creates an up-to-date profile for each student in the school and changes it on the basis of his or her success in learning using his or her learning plan before the student fail. Based on its success rate by following the plan, each student will be given a unique schedule of learning. The student's learning program must include all events in different areas. Teachers must cooperate and inspire each student to improve their learning skills in all fields [27]. Such awareness would allow the teacher to help students achieve their potential and fear of school. This will avoid dropout rate of children. Here, one instructor can teach thirty or more students by applying analytics, even if each has different learning skills and potential. This is called one-to - one or personalized tutoring between a teacher and a student [28].

Through personalized learning, each student is personally focused and can show his mastery in his own field. Personalized learning should make students confident in taking decisions on their own in the right direction [27]. Through technology, the teacher can easily keep track of every student and finds a learning gap, helps in the engaged classroom towards the achievement of the student. New technology will help to improve the relationship between educators, learners and thus the community and will provide resources to meet the specific challenges of students at different ages and stages of learning [29]. Customized programs are made up of cognitive models by gathering input from deep interviews, surveys from schools, educators, students, families, individuals in society, and IT and marketing employees to incorporate customized digital learning [30].

The future classroom should be interactive, digitized and accessed at a remote location. More preferences for MOOCs have been shown by the students. Here students are allowed to choose a course of their choice [31].

Right technology tools mobile phones, applications, cognitive assistants, connected objects will together create a personal learning environment where students can easily meet with teachers and discuss subjects in a virtual space. Such technologies will also allow students to ask questions and answers in an interactive manner. Augmented reality and virtual reality together improve customized learning. As a result, the teacher can focus on the individual student, and the teacher can address his 
doubt anywhere and at any time [31]. More and more training is needed in personalized learning for educators to educate students [29].

\section{WATSON EDUCATION CLASSROOM :}

Watson Education Classroom is a cloud service platform that helps educators incorporates personalized learning in education. Using this, teachers can collect bulk data to understand the requirements of the student's activities and can prepare a lesson plan, student schedule, progress and outcome etc. Cognitive programs are incorporating personalized education through this classroom. The entire learning process of the student's experience is structured through this classroom [32].

\section{ACADEMIC INITIATIVES :}

- IBM MobileFirstapp for iOS and iPads:IBM Watson launched the first MobileFirst Education app for iPad and iOS called IBM Watson Element for Educators. It allows K-12 students and teachers to learn on a personalized basis. Teachers can, at their fingertips, have access to student's interests, attendance, learning activities and style, etc. towards success. Using this tool, teachers can get to know students beyond their academic performance [33]. There, the teacher can insert notes to the app so that the absentees can collect the information taught in the classroom. The unique feature called "spotlight" in the app, can have a special focus on the student by the teacher lets the other teacher know about the student's talent. The App will also have features such as opportunities to involve the classroom through communication, the teacher's main role is to concentrate each student's knowledge and monitor academic progress towards learning standards.

- Tabtor Math: It is built to understand students' minds by the keystrokes they touch as they solve problems. It's connected with IBM Watson to help teachers understand that student's problems with the solution. This increases the student's learning outcomes by increasing the rate of understanding of subjects by $90 \%[34]$.

- Many mobile language applications help millions of students learn foreign languages on their own. They will provide adaptive learning algorithms. A recent math app trial built for children in Malawi. The students will only be able to make progress in six weeks, which will take 12 to 18 months of traditional teaching methods [38].

- IBM's Medical Minecraft game can move through the human body. Health encyclopedia is digested as input from IBM to implement this game. AI and NLP together give the student a feeling of going inside the human body and disease. Using this game, students can grasp subjects with ease [35].

- Teachers TryScience is a web site developed by IBM for teachers. Forty lakh teachers in the Indian Open Educational Resources Community are using STEM to get STEM-related hands-on lessons, resources, teaching strategies and other support for teaching. It is written in 9 Indian languages and covers 12 Indian states. The page also offers some opportunities for teachers to share their opinions with other educators in order to improve their practices [36].

- THINK app: It is free of charge for iPad and 10"Android tablets developed by IBM. This provides students with access to a systematic approach through a series of methods, Seeing, Mapping, Understanding, Believing and Acting (SMUBA). Here students can seek technologies and take part in different STEM systems with hands-on lessons of experience and practice [37].

- The Next Generation Science Standards (NGSS) will help students study science as a fun and interesting subject. Here, teachers will have high standard materials and resources of high quality. Educators Evaluating Quality with NGSS uses the advanced use of Techers TryScience Advanced Tools for updating and examining the current science K12 courses. Using the EQuIP process the New York Hall of Science (NYSCI) initiative, educators have revised existing lessons and updated more active, insightful lessons. The EQuIP rubric process is used by educators to continually update and refine lessons and resources on the basis of feedback and suggestions. It is also used to find the strength and weakness of every lesson [38].

- IBM has created a game, Cognitoys Dinosaurs that provides answers to questions, tells bedtime stories, and plays interactive games, etc. with children [39].

- Sesame Workshop: This is the cognitive learning platform; here, sesame street characters like Grover and Elmo were created to educate children on their own. Such characters should educate students to playful and age-appropriate interactions for fun and knowledge. This offers more applications, games, 
learning toys, etc. to engage students in enjoyable education. It also provides a vocabulary app for kindergarten children, which helps children pronounce challenging words with ease. The cognitive tutor reads the minds of students whether they are struggling to get things done and offers the right solution and advice to make things easier and make progress. Here, students are going to be busy studying in and out of classes [39].

\section{SWOC ANALYSIS OF IBM WATSON WITH RESPECT TO COGNITIVE SERVICES :}

In the technology industry, IBM is a multinational giant. IBM's services include services, corporate software, systems and financial solutions for advisory services and implementation. Basically, all IBM products and services are developed in cognitive engineering. The business and start-ups build Watson's cognitive apps. IBM's ultimate aim is to make better decisions using cognitive computing for every business and profession. Billions of text documents contain large amounts of data that IBM Watson reads and processes with various sources in just a few seconds. This speed helps the business activities on the market to grow. Large volumes of unstructured data between various sectors, such as retail, medical services, education and finance, require cognitive system data analysis.

Strength in SWOC analysis:

Leaner and More Efficient Business Processes: To sustain long-term business growth, IBM provides services, IT solutions and systems for customers and shareholders. Enormous real data are collected and analyzed to find new creative patterns and future business opportunities through cognitive computing are identified. Watson can analyze the processes and dynamically reduce the risk.

Being Updated: In demand for its growth, Company integrates new technologies such as data analytics and cognitive computing. MongoDB, Redis, Elasticsearch and PostgreSQL were acquired, and over 17 billion dollars in over 30 acquisitions were invested. Watson is designed to build on cognitive computing innovations.

Accurate Data Analysis: IBM Watson is used in healthcare, education, industry and so on to use robotic process automation to interpret the related data from the respective sources. Here teacher, employee or physician is not replaced; simply by making appropriate decisions, cognitive computing is used to increase the speed of the data analysis.

Improved Customer Interaction: By avoiding the other staff members, the technology, Robotic process automation generates customer engagement with minimal, contextual details. This improves customer service by having them engaged with a company.

R\&D: IBM has a dedicated research and development center to develop the latest revolutionary technologies. Annual contributions are made for research and development. Watson has launched R\&D goods to offer greater emphasis to opportunities for growth and value.

Weakness in SWOC analysis:

Brand Value drop: IBM was facing a major decline in its brand value. The data provided shows a $\$ 3.642$ billion turn down in its brand value.

Litigations: From time to time, IBM participated in legal proceedings and ongoing conflicts. These disputes misrepresent the company and in fact damage the brand's reputation.

Opportunities in the SWOT analysis:

Data Analytics: More work on Watson contributes to startups being generated to grow cognitive software. It also has a twitter link to include its huge data in the cloud-based data analytics of IBM. Cognitive processing reaches the boundaries of human experience.

Cloud-based solutions: The cloud services requirement has become more common. Public-based cloud services have put 33 percent higher demand.

Company Expansion: IBM develops personal apps with ease with Apple's partnership and IBM's company sees more development. Global consulting operations are planned around the world.

Challenges in the SWOT Analysis:

Barriers to adoption: Cognitive computing takes time to incorporate Watson and its services into an organization, as it does not explicitly process structured data. The biggest obstacle is that only bigger companies can afford Watson. 
Competition: Accenture, Amazon, CSC, Fujitsu and Hewlett Packard are the rival firms with the IBM. They do have tech rivals like CA, Microsoft, Oracle and SAP. IBM is pursuing emerging technology and competing with IBM, Dell, EMC, HP and Oracle innovations.

Global Economy: Currency fluctuations can affect the sales and earnings per share. Labor, shipping and supplies costs are too high with multinational enterprises.

Table 2: SWOC Analysis of IBM Watson

\begin{tabular}{|c|c|}
\hline Strengths & Weakness \\
\hline $\begin{array}{ll}\text { - } & \text { Leaner and More Efficient Business } \\
& \text { Processes } \\
\text { - } & \text { Being Updated } \\
\text { - } & \text { Accurate Data Analysis } \\
\text { - Improved Customer Interaction } \\
\text { - }\end{array}$ & $\begin{array}{ll}\text { - } & \text { Brand Value drop } \\
\text { - } & \text { Litigations }\end{array}$ \\
\hline Opportunities & Challenges \\
\hline $\begin{array}{ll}\text { - } & \text { Data Analytics } \\
\text { - } & \text { Cloud-based solutions } \\
\text { - } & \text { Company Expansion } \\
\end{array}$ & $\begin{array}{ll}\text { - } & \text { Barriers to adoption } \\
\text { - } & \text { Competition } \\
\text { - } & \text { Global Economy }\end{array}$ \\
\hline
\end{tabular}

\section{RECOMMENDATIONS AND SUGGESTIONS :}

Based on the analysis on Watson, we propose further suggestions:

- IBM Watson has 750 servers with its DeepQA software and super power, each server costs 1 million dollar to purchase. A one-server meets the minimum Watson operating requirement. As the technology improves, IBM expects costs to substantially decrease in reaching smaller organizations within a decade.

- As Watson process only unstructured data, cognitive computing requires extra time. The new ways of technologies to be improved to avoid such things.

- If there is any policy change by government, this factor should be taken into consideration in the cognitive model (risk analysis), otherwise human intervention needs to take final decision.

- Watson with cognitive computing and new technologies at first need to train data to understand the process and improve. Such systems / products need long cycles of development. Therefore, technologies to be improved with less training period will be effective.

\section{CONCLUSION :}

In the digital era, the transformation of life is also expected to change education. The future of children is influenced by schooling. IBM is developing better future cognitive learning methods. Such approaches have been continuously updated by IBM Watson, a cognitive tool which uses human input in the right direction to build a student in his career. IBM Watson Education has reached more than 2 Lakh students in different countries around the world. Watson Tutor has shown that the student performance has improved by $40 \%$ and is assessed by A / B experiment done by IBM.

\section{REFERENCES :}

[1] Misal, D. (2018). How The Education Sector Is Using Data Analytics To Revamp Pedagogy. Analytics India Magazine. Retrieved from https://analyticsindiamag.com/how-the-educationsector-is-using-data-analytics-to-revamp-pedagogy/ on 13/03/2020.

[2] Wikipedia. (2019). Watson (computer). Wikipedia. Retrieved from https://en.wikipedia.org/wiki/Watson_(computer) on 01/04/2020.

[3] 8 Ways To Make Educational Institutions More Efficient With Analytics. IBM Big Data \& Analytics Hub. Retrieved from https://www.ibmbigdatahub.com/blog/8-ways-make-educationalinstitutions-more-efficient-analytics on 01/04/2020. 
[4] Lally, A., \& Fodor, P. (2011). Natural language processing with prolog in the IBM watson system. The Association for Logic Programming (ALP) Newsletter.

[5] Arnaout, R. (2012). Elementary, My Dear Doctor Watson. Clinical Chemistry, 58(6), 986-988. DOI: https://doi.org/10.1373/clinchem.2011.180992.

[6] Brown, E. W. (2013). The Jeopardy! challenge and beyond. In Proceeding of the 12th IEEE International conference on Cognitive Informatics \& Cognitive Computing (ICCI* CC). 1020, DOI: https://doi.org/10.1145/2348283.2348446.

[7] Exner, P., \& Nugues, P. (2014). REFRACTIVE: An Open Source Tool to Extract Knowledge from Syntactic and Semantic Relations. In LREC (pp. 2584-2589).

[8] Knobelsdorf, M., Kreitz, C., \& Böhne, S. (2014). Teaching theoretical computer science using a cognitive apprenticeship approach. In Proceedings of the 45th ACM technical symposium on Computer science education (pp. 67-72). DOI: https://doi.org/10.1145/2538862.2538944.

[9] Colbert, J. A., \& Chokshi, D. A. (2014). Technology in Medical Education-Osler Meets Watson. J GEN INTERN MED, 29(12), 1584-1585. DOI: https://doi.org/10.1007/s11606-014-2975-x.

[10]Helbing, D. (2015). From Technology-Driven Society to Socially Oriented Technology: The Future of Information Society-Alternatives to Surveillance. Springer, Cham, 95-102. DOI: https://doi.org/10.1007/978-3-319-15078-9 9.

[11] Kollia, I., \& Siolas, G. (2016). Using the IBM Watson cognitive system in educational contexts. In 2016 IEEE Symposium Series on Computational Intelligence (SSCI) (pp. 1-8). IEEE. DOI: https://doi.org/10.1109/ssci.2016.7849999.

[12] Chen, Y., Elenee Argentinis, J., \& Weber, G. (2016). IBM Watson: How Cognitive Computing Can Be Applied to Big Data Challenges in Life Sciences Research. Clinical Therapeutics, 38(4), 688-701. DOI: https://doi.org/10.1016/j.clinthera.2015.12.001.

[13] Chozas, A. C., Memeti, S., \& Pllana, S. (2017). Using Cognitive Computing for Learning Parallel Programming: An IBM Watson Solution. Procedia Computer Science, 108, 2121-2130. DOI: https://doi.org/10.1016/j.procs.2017.05.187

[14]Balogh, Z. (2018). ANALYSIS OF PUBLIC DATA ON SOCIAL NETWORKS WITH IBM WATSON. Acta Inform. Malays., 2(1), 10-11. https://doi.org/10.26480/aim.01.2018.10.11.

[15]Freeman, D., Gupta, S., Smith, D. H., Maja, J. M., Robbins, J., Owen, J. S., ... \& de Castro, A. I. (2019). Watson on the Farm: Using Cloud-Based Artificial Intelligence to Identify Early Indicators of Water Stress. Remote Sensing, 11(22), 2645.

[16] Garcia, C., \& Uzbelger, G. (2020). Artificial Intelligence to Help the Practitioner Choose the Right Treatment: Watson for Oncology. Healthcare and Artificial Intelligence (pp. 81-83). Springer, Cham.

[17] How To Exploit The Insights You Just Discovered With AI - Watson. Watson. Retrieved from https://www.ibm.com/blogs/watson/2018/01/how-to-exploiting-the-insights-you-just-discoveredwith-ai/ on $16 / 04 / 2020$.

[18] Cognitive Services To Improve Your Business Strategy - Watson. Watson. Retrieved from https://www.ibm.com/blogs/watson/2016/07/cognitive-services-improve-businessstrategyon $16 / 04 / 2020$.

[19] Cognitive Learning Content: A Vision for How To Make Learning Deeply Engaging As Well As Intuitive - IBM Education Industry Blog. IBM Education Industry Blog. Retrieved from https://www.ibm.com/blogs/insights-on-business/education/cognitive-learning-content-a-visionfor-how-to-make-learning-deeply-engaging-as-well-as-intuitive/ on 01/04/2020. 
[20]IBM's Watson Education Partners with Scholastic And Edmodo For Classroom Content Recommendations. VentureBeat. Retrieved from https://venturebeat.com/2018/06/26/ibmswatson-education-partners-with-scholastic-and-edmodo-for-classroom-contentrecommendations/ on 01/04/2020.

[21] Watson Education. Retrieved from https://www.ibm.com/watson/education on 01/04/2020.

[22] Education Industry Solutions. Retrieved from https://www.ibm.com/industries/education on $01 / 04 / 2020$.

[23] About. Retrieved from https://cloud.ibm.com/docs/services/discovery?topic=discovery-about on $13 / 11 / 2019$.

[24] fb.com/prajakta.hebbar. (2019). IBM Partners with Indian States To Train 2 Lakh Women For STEM-Related Careers. Analytics India Magazine. Retrieved from https://analyticsindiamag.com/ibm-partners-with-indian-states-to-train-2-lakh-women-for-stemrelated-careers/ on 01/04/2020.

[25] How Cognitive Systems Can Enable Personalized Learning. IBM Education Industry Blog. Retrieved from https://www.ibm.com/blogs/insights-on-business/education/cognitive-systemspersonalized-learning/ on 01/04/2020.

[26] Personalized Learning: What You Need To Know. Retrieved from https://www.understood.org/en/school-learning/partnering-with-childs-school/instructionalstrategies/personalized-learning-what-you-need-to-know on 03/04/2020.

[27] How Cognitive Systems Will Make Personalized Learning A Reality - Watson. Watson. Retrieved from https://www.ibm.com/blogs/watson/2016/05/cognitive-systems-will-make-personalizedlearning-reality/ on 03/04/2020.

[28] https://medium.com/@OfficeofEdTech. (2018). What Is Personalized Learning? Medium. Retrieved from https://medium.com/personalizing-the-learning-experience-insights/what-ispersonalized-learning-bc874799b6f on 03/04/2020.

[29] IBM - The Future Of Personalised Education. Retrieved from https://www.ibm.com/thoughtleadership/technology-market-research/future-education-technology.html on 03/04/2020.

[30] What We Learned About The Future Of Education From You - IBM Education Industry Blog. IBM Education Industry Blog. Retrieved from https://www.ibm.com/blogs/insights-onbusiness/education/learned-future-education/ on 03/04/2020.

[31]IBM Support $\quad$ Community. Retrieved from https://www.ibm.com/mysupport/s/topic/0TO50000000Qei8GAC/watson-educationclassroom?language $=$ en US on 03/04/2020.

[32] IBM MobileFirst For IOS IBM Watson Element For Educators - Overview - India. Retrieved from https://www.ibm.com/in-en/marketplace/watson-element-education-ios-app on 03/04/2020.

[33] Tabtor Math. Retrieved from https://www.ibm.com/case-studies/tabor-math on 03/04/2020.

[34] The Power Of Augmented Education. IBM Cognitive Advantage Reports. Retrieved from https://www.ibm.com/watson/advantage-reports/ai-social-good-education.html on 03/04/2020.

[35] Teachers TryScience. Retrieved from http://teacherstryscience.us- east.mybluemix.net/ on 03/04/2020.

[36] Teachers TryScience. Retrieved from http://teacherstryscience.us-east.mybluemix.net/units/thinkprocess-innovation on 03/04/2020.

[37] Teachers TryScience. Retrieved from http://teacherstryscience.us-east.mybluemix.net/ngss on $03 / 04 / 2020$. 
[38]A Toy Dinosaur Powered By IBM's Watson Supercomputer. WIRED. Retrieved from https://www.wired.com/2015/02/cognitoys-ibm-watson/ on 03/04/2020.

[39] IBM And Sesame Bring Cognitive Education To The Classroom. IBM Education Industry Blog. Retrieved from https://www.ibm.com/blogs/insights-on-business/education/cognitive-educationannouncement/ on 03/04/2020.

[40] https://www.facebook.com/marketing91/. (2017). SWOT Analysis of IBM - IBM Strengths Weaknesses Opportunities Threats. Marketing91. https://www.marketing91.com/swot-analysisibm/ on $08 / 04 / 2020$. 